\title{
EL ÁLBUM DEL MARQUÉS DE LA VICTORIA Y SU APORTACIÓN A LA HISTORIA DEL MUEBLE
}

El libro de Juan José Navarro, primer Marqués de la Victoria, Diccionario demostrativo con la configuración y anatomía de toda la arquitectura naval moderna ${ }^{1}$ es un magnífico estudio sobre la construcción de barcos, escrito en Cádiz entre 1719 y 1756. En su introducción el autor comenta que su objetivo es hacer una obra «útil, importante e instructiva», y realmente lo consigue. Concibe el libro como un diccionario ilustrado, donde su capacidad como dibujante queda bien demostrada a partir de las múltiples reproducciones de todos y cada uno de los elementos que componen un gran navío. Bajo este prisma didáctico apunta que uno de los grandes beneficios de la obra es facilitar «el saber los nombres con toda individualidad y configuración de cada cosa, que en cada clase se demuestra»; pero posiblemente él no se percató que el diccionario transcendería en mucho su época y la temática estrictamente naval. A finales del siglo xx, el Album del Marqués de la Victoria es una interesante fuente de información, con datos útiles para estudios tan alejados del naval, como es el de la historia del mueble.

Ciertamente, esta obra permite avanzar en un campo del conocimiento todavía virgen, el de la terminología de muebles en lengua castellana. Los que trabajamos en temas relativos a la historia de nuestro mobiliario, sabemos la dificultad cotidiana en interpretar correctamente las informaciones localizadas en los documentos Por este motivo, los contenidos del Album del Marqués de la Victoria son de máximo interés, ya que en él se desvela el significado preciso de los nombres de los objetos, al incluirse, junto a estos, un detallado dibujo.

En concreto, para la historia del mueble son de particular relevancia las láminas donde se citan los distintos tipos de madera de los bosques de la Península Ibérica aptos para el uso naval, la que ilustra las herramientas de los carpinteros de la construcción de barcos, las de ensambles de carpintería y la que relaciona los objetos que amueblan los camarotes de los oficiales. Es en esta última lámina donde nos querríamos detener ahora, para extraer de ella una información que podrá ser aplicable en la interpretación de inventarios y otros documentos que utilizamos para descifrar el moblaje de las viviendas.

«Utensilios y Adornos de Cámara y Camarotes de los Xefes y Comandantes de los Navíos» es el título del folio 106 del diccionario. En él el Marqués de la Victoria ilustra y nombra los muebles y otras alhajas que configuran las cámaras de los oficiales en un barco de la primera mitad del siglo XVIII. Muebles contenedores, mesas, lechos, asientos, objetos de iluminación y complementos son representados a partir de minuciosas ilustraciones que ayudan a su buena lectura y nos permiten observar una fuerte dependencia de modelos ingleses coetáneos (Fig. 8).

Iniciamos el repaso de estos objetos de los camarotes principales observando la «cama con su colgadura» que era utilizada por la máxima autoridad del barco. Bajo esta indeterminada denominación se presenta el tradicional lecho de pilares, es decir, aquel con cuatro montantes rematados por pomos, uno en cada ángulo, que soportan una colgadura compuesta de cortinas, cenefa y cielo. Un mismo tipo de tela a flores se utiliza, igualmente, para el cubrecama y el almohadón cilíndrico. Las camas de los oficiales subalternos eran de construcción más simple. Estos descansaban en la «cámara grande» sobre un «catre colgado», cama que pendía del techo por cuerdas cuya estructura, posiblemente desmontable, se ocultaba bajo su correspondiente cielo y cortinas y era configurada por cuatro montantes verticales que se unían a unos sencillos ban-

\footnotetext{
${ }^{1}$ El original se conserva en el Museo Naval. Madrid. Una tirada de 100 ejemplares fue publicado bajo el título Album del Marqués de la Victoria por Lunwerg Editores en Madrid, 1995. A dicha editorial agradecemos la cesión de la ilustración aquí publicada.
} 


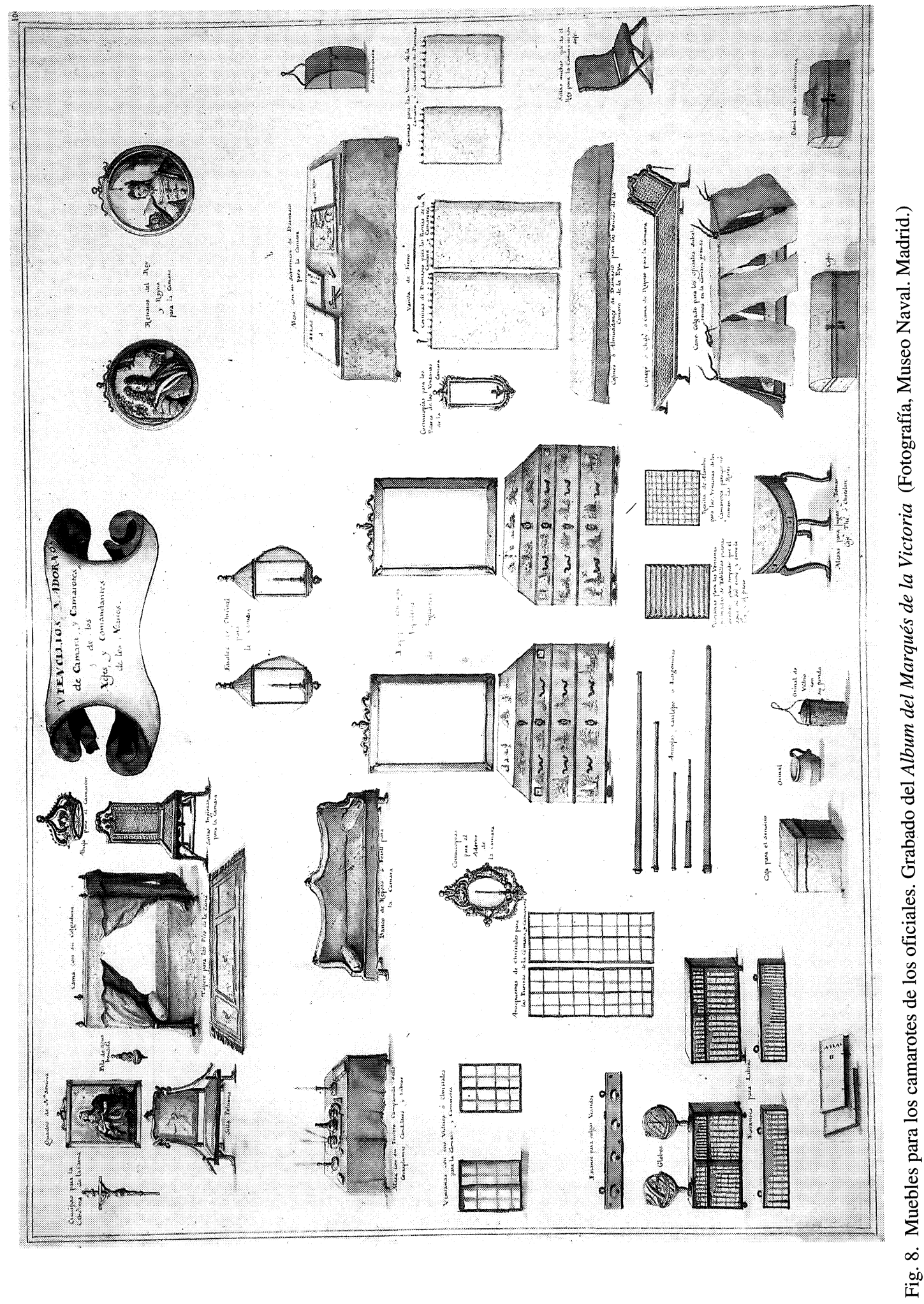


cales. Junto a la cama principal se extiende una alfombrilla, denominada en la época « tapete», — «tapete para los pies de la cámara»- ${ }^{2}$. Para las paredes, pintura de temática religiosa y retratos reales, a semejanza de los salones nobiliarios del periodo. Localizamos un «crucifixo para la cabecera de la cama», un cuadro de La Virgen con el Niño - «quadro de Na. Señora»-, una "pila de agua bendita», una «alhaja para el camarote» que simboliza una corona y un par de tondos con los «retratos del Rey y Reina para la cámara».

A ambos lados del dibujo de la cama principal se disponen dos interesantes modelos de asiento. A la izquierda un sillón denominado «silla poltrona» $y$ a la derecha «sillas inglesas para la cámara», La ilustración que nos ofrece el Marqués de la Victoria para mostrar una silla poltrona coincide con la definición del Diccionario de Autoridades ${ }^{3}$, aunque a través del documento aquí analizado podamos extraer más detalles de cómo era esta tipología en la primera mitad de siglo XVIII. Así pues, comprobamos que la poltrona es un sillón bajo y ancho con asiento y respaldo tapizado. Se distingue de cualquier otro sillón en que su configuración permite reclinar el respaldo. Para ello, los brazos disponen en su parte delantera de orificios que posibilitan la sujección al reposabrazos en distintas posiciones y en su parte posterior la inclinación se consigue a partir de una pieza móvil en forma de S. La silla poltrona aquí presentada lleva el copete tallado con una concha, no dispone de almohadón y su respaldo se sujeta al asiento únicamente por sus montantes verticales.

Por silla inglesa ${ }^{4}$ debemos entender un asiento individual con respaldo y asiento de rejilla y trabajos de talla en el copete. En realidad, lo que vemos ilustrado bajo este término es una de las tipologías de silla inglesa de finales del siglo XVII, dentro del estilo que conocemos como William and Mary, ya en desuso en Inglaterra desde el inicio del siglo XVIII, pero con buena aceptación en las casas españolas a lo largo de toda la centuria ${ }^{5}$.

La última tipología de silla mostrada en esta lámina es la que se utilizaba en los consejos. Con el fin de facilitar su movilidad, dispone de patas plegables, cruzadas en «equis», situadas en los laterales. El asiento y el respaldo se intuyen de tela o cuero, fijados por tachuelas. Este modelo de silla de tijera es descrita en el documento de forma poco precisa, bajo la anotación «sillas nuebas que da el Rey para la Cámara del Consejo».

Para evitar errores en la lectura de otros textos de este periodo, es muy útil constatar como lo que actualmente denominamos sofá, es decir, un asiento para varias personas, tapizado en el asiento, respaldo y bajo los brazos ${ }^{6}$, es nombrado en este documento del siglo XVIII como «banco de reposo o fetoll para la cámara», llevando el aquí presentado el marco de madera visto. Su profundidad se percibe amplia, como para permitir el descanso de una persona en posición estirada y dispone, además, de unos cojines cilíndricos. Este asiento de varias plazas no debe ser confundido con el que Juan José Navarro denomina «canape o chaly o cama de reposo para la cámara». Este último corresponde a lo que conocemos por chaise longue; es decir, una tumbona con asiento individual largo, ideado para reposar las piernas en posición horizontal. Lleva rejilla, patas ca-

${ }^{2}$ El Diccionario de Autoridades, publicado por la Real Academia Española en 1726, define la entrada «tapete» bajo los siguientes términos «alfombra pequeña y manual, u cosa parecida a ella».

${ }^{3}$ Silla poltrona es definida en el Diccionario de Autoridades como «silla mas baxa de brazos que la comun; pero de más magnitud. Suele tener unos hierros con varias muescas, para dexar caer el respaldo todo lo que se quiere, para la mayor conveniencia de la persona, que se recuesta en ella, para el sueño o poltronería de donde tomó el nombre».

${ }^{4}$ Debemos hacer notar como en este documento se utiliza el término «silla» para nombrar el asiento con respaldo y no «taburete» como era habitual en épocas anteriores.

${ }^{5}$ La denominación «cadires a l'anglesa» so muy frecuentes en inventarios post-mortem de ciudadanos de Barcelona de finales de siglo XVIII con nivel de vida material alto y medio-alto. (Consultar nuestro artículo «El mobiliari neoclàssic a Catalunya» en Barcelona: Moble Català, Electa, Generalitat de Catalunya, 1994, p. 74.)

${ }^{6} \mathrm{~J}$. A. Roubo en 1772 ya establece que la diferencia entre canapé y sofá simplemente se deriva de que este último dispone del espacio bajo los brazos rellenos (J. A. Roubo: Le Menuisier en Meubles, París: Inter-Lives, 1989 (1772), p. 652). 
briolé y torneados en los montantes del respaldo, de los que parece pender una cadenilla para, posiblemente, permitir su inclinación. Esta tipología de mueble de descanso penetró en España por influencia francesa junto al término que lo designa, canapé. Pero ya desde ese momento el vocablo canapé fue también aplicado al asiento de varias plazas, que hemos visto que el Marqués de la Victoria denomina banco de reposo, lo que nos provoca las consecuentes dificultades interpretativas ${ }^{7}$. A partir del dibujo no podemos asegurar si sobre la estructura del canapé se colocaba un cojín, como los «cojines o almuadones de damasco para los bancos de cámara de la popa».

Dos son las mesas de trabajo ilustradas. De forma rectangular, van vestidas ocultando completamente su estructura. Una de ellas «con su sobremesa de damasco para la cámara» se utiliza para sostener los mapas y atlas, mientras que en la segunda se dispone el material de escritura « el tintero, campanilla, sello, cortaplumas, candeleros y libros». La tercera mesa representada se utilizaba en momentos de ocio. corresponde a una tipología de gran difusión en los salones europeos de la época, derivada de los cambios de hábitos sociales. Son las «mesas para jugar y tomar café, thé o chocolate», aunque la dibujada en el Album del Marqués de la Victoria sigue los cánones ingleses de hacia 1700; es decir, su forma es todavía circular, con las cuatro patas cabriolé y tres cajoncillos en la cintura.

Es obligado que nos fijemos en la pareja de bellos escritorios bajo espejo que centran la lámina, — «espejos con sus papeleras de Inglaterra»-. Curiosamente, el Marqués de la Victoria mantiene el viejo término «papelera» aplicado, no a una arquilla o escritorio de tradición renacentista, sino a un mueble aparecido en Europa a finales del siglo XVII, cuya estructura responde a una cómoda con la parte superior abatible en forma de pupitre ${ }^{8}$. Este nuevo contenedor se difundió por la Península Ibérica, especialmente en su litoral, ganando acepción sobre arcas y arquillas. En la segunda mitad de siglo XVIII se había convertido en uno de los muebles más remarcables de las viviendas, sobre todo cuando incorporaba un cuerpo superior, ya fuera armario o vitrina. Magníficos ejemplos perviven desde la costa gerundense hasta Portugal. La pareja aquí presentada procedía de Inglaterra y, según se percibe, estaría decorada al charol, técnica que los ingleses denominan «japanning», de fuerte demanda en toda España, especialmente con su fondo de color rojo ${ }^{9}$. El hecho de que se presenten para un barco dos papeleras nos induce a re-

7 Si como hemos visto, para el Marqués de la Victoria canapé es un asiento tipo chaise longue, en el Diccionario de Autoridades de 1729 canapé se define como un «Banco a manera de los escaños, que se usan en España con su respaldo, para acostarse o sentarse junto a la lumbre. Diferenciase en que el canapé tiene colchado el asiento y respaldo para mayor comodidad, y con dos almohadas, para echar encima la cabeza. Es voz francesa nuevamente introducida».

${ }^{8}$ El significado de los vocablos «papelera» y «escritorio» varían con el paso del tiempo, refiriéndose a distintas tipologías de muebles para guardar papeles. El Diccionario de Autoridades todavía define papelera como el «escritorio con sus separaciones y sus puertas o gavetas, para tener y guardar papeles», mientras que la tipología de mueble que el Marqués de la Victoria denomina papelera es otra nueva, que también la encontramos muchas veces nombrada bajo el vocablo escritorio. Los términos papelera y escritorio, ya existentes en el lenguaje, pasan a definir a lo largo del siglo XVIII el mueble aquí representado, de nueva creación. Por su parte, Casto Castellanos en su estudio sobre el inventario de los bienes del Marqués de la Ensenada, datado en 1754, relaciona el término papelera con el «cartonnier» francés. (Consultar Casto Castellanos «La decoración y el mobiliario de los salones madrileños durante el reinado de Fernando VI: El «Menaje» del Palacio del Marqués de la Ensenada» en Catálogo II Salón de Anticuario en el Barrio de Salamanca, Madrid, 1992).

Aprovechamos para hacer notar que la palabra catalana «canterano», usada actualmente para nombrar este tipo de cómoda-escritorio o buró, no significaba en el siglo XVIII el citado mueble, sino el armario o vitrina que podía éste llevar encima. (Consultar el capítulo «Algunas aportaciones terminológicas para el estudio del mueble» en nuestra tesis de licenciatura Los mueblistas de Barcelona a finales del siglo xviii, Universidad de Barcelona, 1997).

9 R. W. Symonds es quien ha documentado este comercio de muebles de Inglaterra a España. Los datos por él aportados nos informan de un importante flujo de muebles decorados imitando las lacas orientales. De entre los artesanos que trabajaron expresamente par este mercado conocemos, a través del citado autor, la figura de Giles Grendey (1693-1780) ensamblador que suministraba a los clientes españoles asientos, mesas y otros soportes. (R. W. Symonds «Giles Grendey and the export trade of English furniture to Spain», Apollo, vol. XXII, dic. 1935, pp. 337-342 y R. W. Symonds «English eighteenth century furniture exports to Spain and Portugal», The Burlington Magazine, vol. LXVIII, 1941, pp. 57-60.) 
flexionar sobre el arraigo, de tradición continental, de colocar muebles por parejas, algo no común, en cambio, en Inglaterra.

Si espejos y cornucopias se multiplicaron en los salones europeos de la primera mitad de siglo XVIII en busca de luz y fantasía, éstos tienen también su lugar en los camarotes, convertidos en hogares por unas semanas o meses. Los espejos colocados sobre las papeleras son del tamaño de medio cuerpo, con sencillo marco rectangular. La existencia de cornucopias en casas de nivel material medio y alto era muy considerable ya que su precio más económico que el de los espejos las hacían atractivas e igualmente útiles. Del mismo modo, la presencia en los camarotes de los navíos de estas pequeñas lunas con mecheros es también abundante. Un modelo ovalado y profusamente tallado lo ofrece el Marqués de la Victoria para «el adorno de la cámara», mientras que los concebidos para los «pilares de las ventanas» son de configuración más simple ${ }^{10}$. El resto de iluminación para estos camarotes se conseguía a partir de los «faroles de christal para la cámara», con una luz cada uno.

Para guardar la ropa personal se utilizaba, además de las citadas papeleras, un «cofre» y un «baúl con su sombrerera» ${ }^{11}$. Ambos se ilustran en forma rectangular, con tapa convexa, falleba y sin aldabas. Sus estructuras parecen estar cubiertas por retales de cuero o tejido. El centro de la tapa del baúl presenta una prominencia donde encaja el sombrero, evitando sus deformaciones. Otra sombrerera con el frente convexo cuelga de la pared.

Los libros eran depositados en «estantes para libros». Bajo esta denominación se entiende, tanto un mueble contenedor con anaqueles, cuyo tablero superior sirve de mesa para sujetar los "globos», como pequeñas estanterías que cuelgan de la pared. A partir de este documento podemos descubrir que también bajo el término estante — «estante para colgar vestidos»- se podía nombrar en la época los colgadores para ropa, a pesar de existir el vocablo percha con el significado actual, esto es, como listón para colgar ropas o vestidos. Por otro lado, alguna pared de estos camarotes principales debía reservarse para colgar los obligados «anteojos, catalejos y largomiras». Finalmente, la «caja para el servicio» con su correspondiente «orinal» $y$ «un orinal de vidrio con su funda» completan los objetos imprescindibles en estas estancias principales de los barcos del siglo XVIII.

Los camarotes disponían de «ventanas con sus vidrios o christales para la cámara y camarotes» que incorporaban una «rexilla de alambre» para evitar la entrada de las ratas y persianas. El mismo marqués nos explica su utilidad: las «persianas de tablillas puestas alistran para impedir que el agua ni el sol entre y entre la luz y el fresco». Igualmente, las puertas llevaban también «antepuertas de christales» Tanto unas aperturas como las otras iban decoradas por «cortinas de damasco», sujetadas por varillas de hierro — «varilla de fierro»- el mismo sistema que encontramos en las viviendas coetáneas.

${ }^{10}$ Aunque en su origen la denominación de comucopia se aplica a un adorno de pared en forma de cuerno de la abundancia con mecheros para colocar bujías y aún siendo de esta manera como lo define por ejemplo el Diccionario de Autoridades en 1726, el Album del Marqués de la Victoria nos demuestra que ya en la primera mitad de siglo XVIII la cornucopia podía adquirir distintas hechuras, no siempre excesivamente trabajadas. La existencia de estas versiones más sencillas de comucopia permiten entender su continua localización en viviendas españolas de la época, incluso en casas de artesanos. (Su presencia la hemos constatado en algunas viviendas de carpinteros y escultores barceloneses de la segunda mitad del siglo. Consultar nuestra tesis de licenciatura, opus cit.).

11 Según se desprendería de este documento, la diferencia entre cofre y baúl podría ser una cuestión de tamaño y no de materiales o estructura. En cambio, en el Diccionario de Autoridades, la diferencia se establece a partir de la forma y posiblemente de los materiales ya que en este diccionario se define baúl como un «cofre redondo, menos por la parte inferior, que es llana y hace assiento como el de la arca», mientras que cofre es «cierto género de arca o baúl de hechura tumbada, aforrado por de fuera en pellejos de caballo u otro animal, y por de dentro en lienzo u otra cosa semejante, que sirve para guardar todo género de ropas. Viene del francés Coffre, que significa esto mismo». Por su parte, las arcas ilustradas en otras láminas del libro de Juan José Navarro se muestran de gran tamaño con la tapa plana. En ocasiones incorporan aldabas, como «la arca para la mantelería» de la lámina 104, y en otras carecen de ellas, como la «arca de la capilla». 
Este análisis de los objetos de mayor estimación de un gran barco del siglo XVII español, nos permite reflexionar sobre su parentesco con los muebles y demás alhajas de las viviendas nobles. Lógicamente, para poder cumplir con su cometido, los camarotes debían ser concebidos bajo mayores criterios de practicidad, pero las necesidades no impedían que el capitán y demás oficiales pudieran disfrutar durante sus largas travesías de unos ambientes y objetos cercanos a los de sus propios hogares. La colocación en estos barcos de muebles no estrictamente imprescindibles, como el canapé, el banco de reposo o los espejos, es sólo posible gracias a la extensión de conceptos como el lujo y confort entre los ciudadanos de las clases acomodadas. Como es bien sabido, este periodo de nuestra historia es uno de los más creativos en la decoración de interiores europea, bajo el protagonismo de Francia e Inglaterra. El resto de naciones aceptan las novedades con más o menos celeridad, y España no es una excepción. Si a través de inventarios de viviendas descubrimos la introducción de estas innovaciones en las distintas ciudades españolas ${ }^{12}$, el Album del Marqués de la Victoria nos ayuda, además, a comprender cómo estas nuevas costumbres quedaron bien asentadas en la primera mitad de siglo XVIII en España. La presencia de una mesa de juego o una poltrona en un camarote sólo tiene sentido si para los oficiales del barco, que eran sus usuarios, estos muebles habían alcanzado la calidad de bienes de uso cotidiano.

Aunque Juan José Navarro, primer Marqués de la Victoria no pueda ser considerado un experto en mobiliario, el folio 106 de su libro es, sin duda, uno de los más importantes testimonios a nuestro alcance para comprender el significado de los nombres de los muebles empleados en castellano en el siglo XVIII. Su aportación es mucho más valiosa que la de cientos de documentos de difícil lectura. El nos ofrece imágenes y estas, en ocasiones, valen más que mil palabras.

Mónica Piera Miquel

${ }_{12}$ El inventario de bienes del palacio de D. Cenón de Somodevilla, Marqués de la Ensenada de 1754 es uno de los relativos al siglo XVIII analizado desde el punto de vista de su decoración y mobiliario. (Ver nota n. ${ }^{\circ}$.) 